\title{
A EXPERIÊNCIA DE ALFABETIZAÇÃO DIGITAL NAS TOTALIDADES INICIAIS DA MODALIDADE EJA
}

\section{THE EXPERIENCE OF DIGITAL LITERACY IN THE INITIAL TOTALI- TIES OF THE EJA MODE}

DOI: http://dx.doi.org/10.5965/1984317815022019008

\author{
Valeria Gonzatti \\ valeriagonzatti@gmail.com \\ Andrea Reginatto \\ andrea.reginatto@gmail.com
}

\begin{abstract}
RESUMO
O presente artigo é fruto de inquietações acerca de minha prática como educadora da rede estadual na Modalidade Educação de Jovens e Adultos (EJA). Os estudantes das Totalidades Iniciais estão na alfabetização. A experiência com a alfabetização digital nas turmas iniciais pode proporcionar novas e efetivas aprendizagens. Essa pesquisa seguiu um delineamento qualitativo através de estudo de caso (YIN, 2005). Os participantes foram três estudantes que frequentam as Totalidades Inicias da EJA numa escola estadual do município de Canoas/RS. O critério de seleção foi de pertencer à modalidade EJA, ser maior de 18 anos e ser voluntario. $O$ instrumento de pesquisa foi a entrevista semiestruturada. $A$ análise de conteúdo (BARDIN, 1977). identificou as seguintes categorias emergentes: "EJA Chegada", "Facilidades no computador", "Dificuldades na sala digital", "Expectativas com o computador" e "Aprender no computador". Os resultados enfatizam a necessidade de permanente reflexão sobre a alfabetização digital (RIBEIRO, 2017) e o uso dos computadores como forma de prática educacional. Neste contexto, tanto a alfabetização digital como letramento (LIMA \& ALMEIDA, 2015) são importantes para esses estudantes, visto que o uso de computadores e internet os faz mais informados e participativos.
\end{abstract}

Palavras-chave: Educação de Jovens e Adultos (EJA). Alfabetização digital. Estudo de caso.

\begin{abstract}
This article is a restless study of my practice as a network educator in the Youth and Adult Education Mode (EJA). Students of the Initial Totals are in literacy. The experience with digital literacy in the classes is capable of new and effective learning. This research followed a qualitative design through the case study (YIN, 2005). The participants were three students who attended as Total Initiatives of the EJA in a state school in the municipality of Canoas / RS. The selection criterion was to belong to the EJA modality, to be over 18 years old and to be a volunteer. The research instrument was a semi-structured interview. A content analysis (BARDIN, 1977). "EJA - Arrival", "Difficulties in the digital room", "Expectations with the computer" and "Learning in the computer". The values are based on a critical analysis of digital literacy (RIBEIRO, 2017) and the use of resources as a form of educational practice. In this context, both digital literacy and literacy (LIMA \& ALMEIDA, 2015) are important for students, since the use of computers and the Internet are more informed and participatory.
\end{abstract}

Keywords: Youth and Adult Education (EJA). Digital literacy. Case study. 


\section{INTRODUÇÃO}

Os computadores e smartphones fazem parte do dia-a-dia das pessoas. $\mathrm{O}$ emprego de dispositivos e o acesso à internet em escolas vem crescendo com o passar dos anos. Mesmo com tais informações existem estudantes que não tem acesso ou não fazem uso dos dispositivos. Para Coscarelli (2017), o computador faz parte da vida, como do lazer e da comunicação e é uma demanda de muitos ambientes. O tema proposto para este artigo centra o olhar na alfabetização digital de estudantes da modalidade de Educação de Jovens e Adultos (EJA) de uma escola pública, estadual, da região metropolitana de Porto Alegre. A escola recebe estudantes de todo município, por estar em uma área central da cidade. Os participantes da pesquisa foram estudantes das Totalidades Iniciais (1 e 2) que correspondem aos anos iniciais do ensino fundamental. As turmas são compostas por estudantes adultos, maiores de 18 anos, em fases de alfabetização e pós-alfabetização. Assim, problema de pesquisa desse artigo foi: Como se dá o processo de alfabetização digital em estudantes da modalidade EJA sem convívio com as Tecnologias de Informação e Comunicação? Assim, o objetivo geral foi investigar o processo de alfabetização digital de estudantes inseridos na alfabetização da modalidade EJA. Como objetivos específicos delimitam-se: I. Elencar as expectativas sobre a alfabetização digital, II. Relacionar as facilidades e as dificuldades da alfabetização digital de estudantes da EJA.

A ideia de construir a pesquisa que envolve o tema da alfabetização digital se justifica, pois, além de minha experiência de quinze anos na educação, a modalidade EJA é carente de recursos, tanto físicos como humanos, para o uso contínuo da sala digital. Para atender aos objetivos propostos este estudo está organizado em quatro seções: fundamentação teórica; metodologia da pesquisa; análise e discussão dos resultados; e considerações finais.

\section{FUNDAMENTAÇÃO TEÓRICA}

A fundamentação teórica está dividida nas seguintes seções: Modalidade EJA e Inclusão Digital. Esses pontos darão suporte teórico sobre a temática do estudo. 


\subsection{Modalidade EJA}

A Educação de Jovens e Adultos por vezes é o destino daqueles que não tiveram acesso ou oportunidade de estudos na educação básica na idade própria. Como idade esperada para educação básica está o período de 04 aos 17 anos (do ensino infantil ao ensino médio). A EJA, no ensino fundamental, aceita jovens a partir de 15 anos. A modalidade regula suas diretrizes nos princípios da Lei de Diretrizes e Bases da Educação (LDB), Lei n 9394/96 (BRASIL, 1996) que são: a igualdade de condições para o acesso e a permanência na escola, o pluralismo de ideias e de concepções pedagógicas, a garantia de qualidade de ensino, valorização da experiência escolar anterior e vinculação entre a educação escolar, o trabalho e as práticas sociais (BRASIL,1996).

Segundo a LDB, Lei n 9394/96 (BRASIL,1996), a EJA utiliza uma metodologia diferenciada que contempla uma análise e avaliação de estudos formais e informais do educando, a fim de situar um patamar para aprendizagem possibilitando que prossiga, de acordo com os Planos de Estudos da escola.

Sabe-se que:

A Educação de Jovens e Adultos (EJA) surge como uma medida paliativa no atendimento dessa população que retorna à escola com vistas ao mercado de trabalho. No entanto, um novo perfil de alunos adentra a essa modalidade de ensino básico, entre eles, temos o idoso (LOPES \& BURGARDT, 2013, p.312).

A noção de atividade compensatória, como uma reposição de estudos da infância e adolescência, está presente na história da modalidade EJA e esse aspecto pode ser considerado uma barreira no desenvolvimento das atividades (JOAQUIM \& PESCE, 2016). Desta forma a modalidade EJA atende pessoas com diferentes histórias de vida. A aprendizagem formal da escola regular deve integrar os aprendizados de vida relacionados aos estudos informais dos estudantes. A prioridade, para essa população, será além da permanência nos bancos escolares a promoção da cidadania integrando saberes antigos e atualizados.

Na modalidade o educador busca um currículo transformador para educandos que vem de um ensino tradicional. Assim, o uso de tecnologias pode ser uma nova competência dos docentes (VASCONCELOS, DA SILVA \& DA SILVA, 2018). 


\subsection{Inclusão Digital}

Inclusão digital não é somente oferecer computadores para garantir a educação e o aprendizado dos estudantes. A oferta de equipamentos é condição necessária, mas não suficiente para se realizar uma verdadeira democratização do acesso as tecnologias. A inserção de todos na sociedade da informação ocorre quando o indivíduo utiliza a informática como um meio de acesso à educação, ao trabalho, às relações sociais, à comunicação e ao exercício de sua cidadania. Incluir o indivíduo digital e socialmente requer ações que the ofereçam condições de autonomia e habilidade cognitiva para compreender e atuar na sociedade informacional (DE SOUZA SILVA, SILVA; DE ALBUQUERQUE, 2016). A alfabetização letrada e a alfabetização digital democratizam o conhecimento no público da modalidade EJA (NUNCIATO, 2009).

O uso de tecnologias, de acordo com o contexto histórico da inclusão digital na EJA, se deu pelo uso de material referente aos recursos tecnológicos de apoio, começando pelo uso de aparelhos de áudio, projetores, computadores, pen-drives até chegar as lousas virtuais. A proposta pedagógica bem elaborada junto as novas tecnologias buscam validar a aprendizagem tanto para discentes quando docentes. (VASCONCELOS, DA SILVA \& DA SILVA, 2018).

Os educandos que frequentam as salas de aula da modalidade em estudo estão, mesmo analfabetos, imersos em novas tecnologias (DA SILVA; AZEVEDO; DE ANDRADE, 2012). Aos estudantes maiores de 60 anos, procura-se rever o currículo, a maneira de propor os conteúdos, as metodologias, o material didático e a possível utilização das tecnologias. Para Lopes e Burgardt (2013), o computador é uma das ferramentas que produzirá novos métodos de alfabetização, no qual os educadores poderão propor atividades que irão atender peculiaridades dos idosos, como, por exemplo, o tamanho de letra.

Assim:

Tendo em vista a atual sociedade dotada de recursos tecnológicos, compreendemos que as TICs devem ser elementos didáticos e de qualificação da alfabetização e letramento dos sujeitos envolvidos na EJA, para que, de fato, seus participantes tenham acesso e possam ser incluídos no processo de informatização da sociedade, e sua alfabetização seja qualificada e promotora de letramentos digitais (LIMA \& ALMEIDA, 2015, p.7). 
O retorno às salas de aula com objetivo de retomar ao mundo e, possivelmente, ao mercado de trabalho, traz as questões do uso digital devido às ocupações laborais e também a participação na sociedade (LOPES \& BURGARDT, 2013). Em uma revisão da literatura foram observadas três disposições na qual a primeira afirmou que existem poucos estudos sobre a formação de professores, tecnologias da informação e a modalidade EJA; a segunda disposição defende que há concordância entre os autores de que o uso das TICs (Tecnologias de Informação e Comunicação) na modalidade EJA contribui para aprendizagem de estudantes; a terceira disposição apontada foi que os estudos instigam a utilização das TICs de maneira mais crítica (JOAQUIM \& PESCE, 2016).

Assim, a alfabetização digital não será somente um novo espaço de escrita, será também um novo significado de mundo e espaços de circulação. De tal modo, os alfabetizados, fazem parte do grupo que consegue, efetivamente, ser competente em diferentes eventos de letramento (comunicação visual, auditiva, espacial). Um desses eventos pode ser o uso de computadores em uma sala digital. O estudante alfabetizado será aquele que sabe ler e escrever. O estudante letrado será capaz de ler e escrever, mas que corresponde adequadamente às demandas sociais da leitura e da escrita. Isso proporciona uma nova maneira de interação (textos, mídias, gravuras, fotos) e relacionamento entre os estudantes e sua aprendizagem através da conectividade (RIBEIRO, 2017).

\section{METODOLOGIA DE PESQUISA}

A pesquisa em questão terá delineamento descritivo de cunho qualitativo caracterizando um estudo de caso. Para Yin (2005) o estudo de caso possibilita uma investigação que busca preservar as características holísticas e significativas dos eventos. Os sujeitos deste estudo participaram de entrevistas que são fontes essenciais de informações para estudos de caso. Com as entrevista foi possível construir as categorias e analisar os temas emergentes. A análise de conteúdo se constitui a fim de descrever o tópico emitido no processo de comunicação, seja ele por meio de falas ou de textos. Desta forma, essa análise é composta por procedimentos sistemáticos que proporcionam o levantamento de indicadores sejam eles quantitativos 
ou qualitativos, permitindo a realização de inferência de conhecimentos (BARDIN, 1977).

De acordo com Moraes (2006) o primeiro passo metodológico é a interpretação da leitura na busca de sentido para as unidades de base dos dados coletados. Neste ponto da análise se buscou separar aquilo que é importante e depois elencar as unidades de sentido. Estes passos fazem o pesquisador conhecer o que está por trás de cada mensagem. A categorização, para Minayo (2007), consiste num processo de redução do texto às palavras e expressões significativas. Na perspectiva da análise do conteúdo (BARDIN,1977), as categorias são vistas como sinais ou camadas que agrupam determinados elementos reunindo características comuns.

Em relação ao contexto da investigação para coleta de material, a pesquisa foi desenvolvida em uma escola estadual, de uma região metropolitana de Porto Alegre, que oferta ensino fundamental regular durante o período diurno e a Modalidade EJA no período noturno. Na Modalidade EJA, objeto do estudo de caso, o público é de estudantes de diferentes faixas etárias (15 aos 70 anos) e diferentes momentos de aprendizagem (início do processo de alfabetização, retorno aos bancos escolares ou troca de turno). São características especificas dos discentes das Totalidades Iniciais da EJA jovens e adultos analfabetos, alfabetizados e pessoas com deficiência intelectual.

Foram participantes do estudo os educandos das Totalidades Iniciais (T1 e T2) da escola da rede estadual do município de Canoas (RS) que, após assinatura do TCLE (Termo de Consentimento Livre e Esclarecido), aceitaram participar da entrevista. Os critérios de inclusão foram (1) ser estudante da modalidade EJA na escola proposta, (2) ter idade superior a 18 anos, (3) aceitar participar da pesquisa. Os critérios de exclusão foram (1) ter idade inferior a 18 anos, (2) discordar em participar do estudo e (3) apresentar problemas sensoriais primários (auditivo e visual) não corrigidos (uso de aparelho auditivo ou óculos) durante o momento da avaliação. Aos participantes do estudo foi garantido sigilo quanto à sua identidade, sendo informados que sua identidade não seria divulgada e que a participação seria voluntária, que a qualquer momento poderia se retirar do estudo.

Para o desenvolvimento da pesquisa foram realizadas entrevistas semiestruturadas contendo questões referentes à alfabetização e letramento digital. As questões 
que nortearam a entrevista foram: Como viestes a estudar na Modalidade EJA?

Como é pra ti usar a sala digital aqui na EJA? Quais as tuas expectativas em relação ao uso de computadores e internet? Saberias me dizes se a tecnologia possibilita um melhor aprendizado? O estudo seguiu os critérios éticos necessários referentes aos termos consentimentos informados devidamente esclarecidos, voluntariedade e anonimato dos envolvidos.

\section{ANÁLISE E DISCUSSÃO DOS RESULTADOS}

A análise e discussão dos resultados serão apresentados nessa seção com a apresentação das categorias emergentes das entrevistas com os estudantes. As entrevistas foram gravadas e depois transcritas. Assim, participaram do presente estudo três estudantes da Modalidade EJA do ensino fundamental de uma escola estadual do município de Canoas/RS. Partindo das entrevistas e preservando a identidade dos estudantes optou-se pôr utilizar E1 para as falas do estudante 1, seguindo por E2 para as falas do estudante 3 e E3 para as falas do estudante 3. Os voluntários do estudo foram a) um estudante adulto, 28 anos, negro, com deficiência intelectual leve, empregado fazem 10 anos pelo sistema de cotas. O estudante está na modalidade após concluir o ensino na escola especial da cidade que habilitava até a $4^{a}$ série. Com a possibilidade de empregabilidade, após um curso de formação em panificação, foi solicitado a família que o jovem permanecesse estudando. A família encontrou a escola com a EJA e desde 2005 entre indas e vindas, o estudante permanece nos bancos escolares. No momento da pesquisa o jovem permanece empregado na mesma empresa que o contratou após o curso de formação, é um estudante assíduo e interessado, mesmo com muita dificuldade de expressão escrita; b) uma senhora branca, com companheiro, cinquentenária, empregada como cuidadora de idosos, mãe de seis filhos. Retornou a escola após os filhos estarem maiores de idade. É uma estudante com dificuldades na área logico-matemática formal (realizar atividade de multiplicação e divisão, por exemplo), devido Apresenta interesse e busca novas oportunidades de trabalho; e c) uma jovem adulta, com deficiência intelectual leve, desempregada, parda, 21 anos, mãe solo de um filho de 6 anos. A estudante abandonou os estudos diversas vezes devido as suas dificuldades em 
conteúdos escolares. Atualmente está frequentando a Totalidade 1 e já é capaz de escrever pequenas frases e cálculos simples.

\subsection{Análise do conteúdo e categorias}

As categorias emergentes das entrevistas foram: 1.Categoria: EJA - Chegada; 2.Categoria: Facilidade no computador; 3.Categoria: Dificuldades na sala digital; 4. Categoria: Expectativas com o computador e Categoria 5: Aprender no computador.

\subsubsection{CATEGORIA: EJA - Chegada}

A categoria apresenta as percepções acerca de como os estudantes chegaram na modalidade. Os entrevistados tiveram diferentes chegadas na modalidade EJA como a busca após anos sem estudar e a vontade de trocar de escola.

"Aqui é bom... Eu queria vir sozinho, aí vim de noite." E1

A EJA pode ser entendida como a garantia de direito à educação para as pessoas que não tiveram a oportunidade de participar da educação formal na idade adequada (LIMA \& ALMEIDA, 2015). Bins (2007) salienta que enquanto a educação não conseguir atender às tantas adversidades sociais que se instalaram em nossa sociedade, à EJA, enquanto lugar de ensino de excluídos do sistema escolar, social e de aprendizagem terá que prover as necessidades básicas dos sujeitos em seu direito à qualidade de vida. Ou seja, a EJA tomará pra si, como já acontece em diversas escolas, um papel do Estado e que por vezes não conseguirá dar conta da demanda que recebe.

"Daí pedi pra várias pessoas, pra minha filha também. Procura na internet, pra mim, e vê se consegue. Ai ela disse, vou fazer isso então. Ela pesquisou e encontrou o colégio. Olha mãe, tem esse colégio aqui." E2

Os pesquisadores Joaquim e Pesce (2016), em sua revisão de literatura, propõe que a inclusão digital pode ser elencada como facilitador de socialização e potencializando a cidadania. Moraes (2009) lembra que a EJA, além de ser um lugar 
ocupado pelos segmentos discriminados da sociedade brasileira, é também um espaço educacional que assume a diversidade como tônica dessa educação que, historicamente, foi tratada pelas políticas públicas como produção da conformidade. Além de ressaltar a importância da EJA como espaço sociocultural - no qual os jovens e adultos têm autonomia sobre o que falam e o que ouvem.

"Eu já estudava faz tempo... só que eu sai e agora eu entrei de novo. Tinha parado e voltei a estudar. Tinha parado, depois, voltei." E3

Nas falas dos estudantes se observa o desejo de mudança, a busca pelo ensino e questões relacionadas a desistências e retorno aos bancos escolares. Observa-se também que o uso de internet fez parte da pesquisa por um nova escola. $E$ o quanto isso é valorizado atualmente, o saber como pesquisar, colher informações na rede mundial de computadores. Para Joaquim e Pesce (2016) a inclusão digital na modalidade EJA faz parte de um processo de libertação ou empoderamento na vida dos estudantes mais velhos que retornam aos bancos escolares.

\subsubsection{CATEGORIA: Facilidades no computador}

A categoria apresenta as facilidades elencadas sobre o uso do computador na sala digital da escola. $\mathrm{O}$ ato de pesquisar torna o estudante autônomo em sua busca por conhecimento e o valida perante a sociedade. Ações simples como ligar, desligar e saber pesquisar são atuações que tornam os estudantes mais empoderados na sala digital.

"Pra mim é muito bom, é maravilhoso, eu adoro, né. Eu pesquiso tanto música quanto... Ontem, por exemplo, a gente pesquisou sobre Canoas, depois pesquisei sobre receitas maravilhosa que eu gosto de fazer comida, né. Eu gosto muito!" E2

"Olha...agora porque eu muito pouco usava, uso. Muito pouco, quase nada. Agora tá sendo muito bom. Eu agora eu já sei ligar ele, já sei desligar, sabe... pesquisá já. Pra mim agora tá sendo fácil." E2

"Eu aprendo um monte de coisa, assim.... Quando a cabeça da gente fica coisado... quando eu tô com dor de cabeça eu paro um pouco." E1

"As letras é fácil." E3

"É bom olhar, pesquisar a internet, pesquisar as pessoas...mexeno ontem eu apertei sem querer e pesquisei. É bem legal, assim." E1 
O uso de tecnologias da informação e comunicação na modalidade EJA, no estudo de Joaquim e Pesce (2016), alega que o seu uso oportunizará aos estudantes questões referentes a sua emancipação e maior participação como atores sociais. O discurso dos estudantes nessa categoria os coloca como participantes dos momentos digitais da escola. Os alunos relatam as questões de pesquisa, manejo no dispositivo e facilidades no reconhecimento das letras, que na totalidade de alfabetização é admirável.

\subsubsection{CATEGORIA: Dificuldades na sala digital}

A categoria elenca as dificuldades acerca das vivências que aparecem no contexto do uso da sala digital. As principais queixas são relacionadas a motricidade fina em relação ao uso do cursor, memorizar a senha de acesso ao sistema e a digitação de palavras.

"É quando eu mexo assim, de colocar de cima pra baixo (faz o gesto como se usasse o mouse). É ruim eu fico assim, pôr pra cima eu sei." E1

"Eu acho que a gente pode aprendê muito coisa, né. Porque inclusive, como eu tava dizendo pra senhora, a gente deu prioridade, lá em casa, a reforma da casa. Mas agora, assim, faz muita falta." E2

Stobäus, Bins e Mosquera (2012) e Bins (2007) refletem sobre a aprendizagem como processo que possibilita a inclusão social efetiva de adultos, entendendo a contextualização e conhecimentos teóricos sobre inclusão. Nunciato (2009) infere que o uso de plataformas digitais acontece nos mais diferentes locais (bancos, estabelecimentos públicos).

"Senha é mais difícil." E3

"Escrever aquelas palavra comprida é difícil. Escrever palavra comprida no computador." E3

Os estudantes que não estão alfabetizados são percebidos com uma dificuldade maior de utilizar o computador (RIBEIRO, 2017). Para Coscarelli (2017), os ambientes digitais, cada vez mais presentes tanto em nossa vida tanto pessoal 
quanto profissional, requisitam muitas habilidades relacionadas à leitura e à escrita. Como no exposto pelos estudantes elencando suas dificuldades (digitar a senha, escrever palavras compridas e no uso do dispositivo mouse).

\subsubsection{CATEGORIA: Expectativas com o computador}

A categoria traz as expectativas sobre o uso do computador. Dentre as probabilidades são leituras, comunicação com parentes distantes, e ter novas possibilidades de aprendizagens.

"Eu gosto de pensar, eu não tenho computador, mas eu gosto de mexer aqui. Ler as coisas nos computador." E1

"É muita coisa, né, coisa boa, né! Tanto pro colégio como pra casa da gente, quanto pra gente. Até conversar com as gentes, falar com meus familiares em Santa Catarina, eles moram lá. Então é muito importante, né, muito!" E2

No ambiente virtual, como por exemplo em um blog, a leitura dos comentários dispõe os participantes na ocupação de um lugar virtual e a possibilidade de comunicação com viés afetivo (MATIAS \& DE FIGUEIREDO, 2018). Para Nunciato (2009) o computador pode contribuir não apenas para a inclusão digital mas também como um incentivo à aprendizagem. Com isso os estudantes podem se apropriar de questões para além da sala digital como comunicar com pessoas, descobrir fatos e participar de conversas familiares.

"Aprendê mais coisa! Aprender mais coisas pra mim passar de ano, que a minha mãe espera também. E quando tiver maior, fazer bem curso, bem crescido... Quero ser confeiteira!" E3

A educação necessita fazer parte das novas tecnologias e com isso passar por várias transformações. Colegas educadores precisam estar prontos para receber informações de quaisquer meios e avaliar a relevância de cada uma. E assim, serem capazes de proporcionar a inclusão digital. É de suma importância que a atuação qualificada e integrada, dos educadores, seja capaz de orientar o trabalho nas escolas e com isso proporciona a alfabetização digital dos estudantes (DE SOUZA SILVA; SILVA; DE ALBUQUERQUE, 2016). 


\subsubsection{CATEGORIA: Aprender no computador}

A categoria Aprender no computador demonstra as principais questões referentes a aprendizagem no ambiente digital. Para os discentes as aprendizagens são ilimitadas e foram, no momento da entrevista, elencadas como exemplo realizar pesquisas sobre países, jogos, receitas e o simples fato de realizar leituras no computador é descrito como ações que fazem a diferença.

"É pra olhar coisas que ... coisa bonitas, olha os países... olhar os jogos, olhar as pessoas... A cabeça da gente fica melhor!" E1

A tela do computador não é definida apenas como para escrever, como também contribuem para aspectos relativos de produção, reprodução e difusão da escrita e da leitura de diferentes conteúdos, como tornando os sujeitos letrados (SOARES, 2002). Para Nunciato (2009) o uso do computador pode ser entendido como uma alternativa para apropriação de leitura e escrita.

"Eu gosto de pensar, só... quando eu não tenho, eu não tenho computador, mas eu gosto de mexer, no joguinho, pego o livro pra ler, mas eu gosto de mexer aqui. Ler as coisas, ler os computador." $\mathrm{E} 1$

A escrita realizada com o uso do computador é uma nova versão da escrita em papel. Assim, o uso da tecnologia promoverá novas formas de escrever, de obter informação (NUNCIATO, 2009). A educação formal, relativa aos bancos escolares, implica na troca de informações e experiências entre pessoas de gerações e aprendizagens distintas. A inclusão digital pode estimular essas aprendizagens, colaborando para o pleno desenvolvimento do sujeito (BARROS, SILVA \& CISESKI, 2018).Há lacunas sobre às práticas de letramento digital visto que muitos não tem em seus lares computador e acesso internet (SILVA \& SILVA, 2017).

"Vê o mundo, assim, no computador. Aprender coisas novas pra ir pra frente, o negócio é ir pra frente, pra trás não. Pra frente é mais bom." E1

$\mathrm{Na}$ vida contemporânea o letramento digital ocupa a interação antes ocupada pelo letramento tradicional com uso de letra manual (MATIAS \& DE FIGUEIREDO, 
2018). O mundo é digital e por vezes a escola ainda não é. Existe desenvolvimento tecnológico com diversas ferramentas de comunicação digital que abarcam demandas pessoais e profissionais, visto que as pessoas estão na maioria do tempo conectadas. A prática na modalidade EJA deve se propor a esse fim, preparar os estudantes para uma sociedade conectada, globalizada, digital. As TICs são aliadas na efetivação de um ensino mais crítico (SILVA \& SILVA, 2017).

"Ela dá muita informação, dá... meios, né, da gente de pesquisar coisa importante, né. A gente consegue sim... tem tanta coisa que a gente consegue, né, fazer, né, aprende né, com o computador, né." E2

A busca por informações em forma de pesquisa na internet impulsiona a curiosidade e a necessidade da leitura se faz presente, dado que, ler é um requisito para procurar o que se deseja investigar. Esse letramento estimula diferentes capacidades cognitivas, culturais e sociais. Dessa forma, fazer parte do mundo digital proporciona um novo aprender relacionado a leitura e escrita (Nunciato,2009).

De acordo com o INEP (2012) no Censo Escolar 2011 mostra que os alunos que dos anos iniciais do ensino fundamental da EJA têm idade muito superior aos que frequentam os anos finais. Isso implica que as totalidades iniciais não estão causando demanda para os anos finais do ensino fundamental na EJA. Considerando as idades dos alunos nos anos finais do ensino fundamental da EJA, há fortes evidências de que essa modalidade está recebendo alunos provenientes do ensino regular. Tal fator é muito comum na escola estudada e no perfil atual da clientela escolar no qual há poucos adultos e muitos adolescentes, por isso o número tão reduzido de participantes no estudo.

"Os joguinhos, as coisas que tem no computadô ... O que têm? i...tem bastante coisa... Escutar música, vê as coisas que a professora pede, pesquisá! O mais difícil é a senha!" E3

O fato que se observou no decorrer do trabalho é que a escola recebe o desafio da inclusão digital. E o que se espera, ou se almeja não seria uma inclusão de fachada, mas transformadora a fim de promover melhoras significativas na qualidade de vida destes estudantes. As relações humanas são influenciadas pelo uso das mídias digitais sendo um dos recursos de comunicação (MATIAS \& DE FIGUEIREDO, 
2018). A inclusão digital não é somente oferecer computadores para o aprendizado dos estudantes. Alfabetização digital (letramento) deverá incluir o sujeito socialmente, a fim de oferecer condições de autonomia e habilidade cognitiva para compreender e atuar na atual sociedade (DE SOUZA SILVA, SILVA; DE ALBUQUERQUE, 2016).

Enfim, reconhecer os conhecimentos adquiridos ao longo da vida, valorizando, respeitando e reconhecendo as capacidades dos educandos pode auxiliar para que se possa desmistificar a relação com as tecnologias. Silva \& Castro (2017) afirmam que com a chegada das tecnologias informacionais no ambiente escolar, existe a necessidade de se discutir a importância de uma nova modalidade de letramento além do alfabético: o letramento digital. A maior proximidade ao computador proporciona a inclusão e pode desenvolver habilidades para além do manejo da máquina, como também, capacidades cognitivas com softwares (RIBEIRO, 2017). O letramento implica em uma reflexão crítica com o objetivo de permitir aos sujeitos a sua participação em diferentes contextos (sociais e culturais) a fim de garantir a inclusão social (LIMA \& ALMEIDA, 2015).

\section{CONSIDERAÇÕES FINAIS}

A alfabetização digital é uma necessidade atual. Na modalidade de Educação de Jovens e Adultos (EJA), nas totalidades iniciais, isso se torna um empecilho visto que a disponibilização de materiais didáticos para essa modalidade é escassa e muitos educandos, na maioria menos favorecidos economicamente, não tem acesso em suas residências. A modalidade é carente de recursos, tanto físicos como humanos, para o uso contínuo da sala digital. Com a turma de alfabetização da modalidade EJA, na maioria adultos e/ou idosos, que retornaram aos bancos escolares em busca de satisfação pessoal, ler sozinho é um desafio. A alfabetização digital os colocará em outro "mundo". Desta forma, pesquisar sobre esse tema se torna relevante.

As TICs devem fazer parte do dia-a-dia do letramento, visto que atualmente muitas questões cotidianas relacionadas a leitura e da escrita são mediadas pelas tecnologias. As totalidades iniciais, pesquisadas no presente estudo, fazem na me- 
dida do possível o uso das TICs. Mas, nem todas turmas oferecem letramento digital aos estudantes. Negligenciar os estudantes da modalidade ao letramento digital pode ser entendido como negar um direito (LIMA \& ALMEIDA, 2015). A palavra letramento, dessa forma, é concebida como um conceito plural no qual as diferentes tecnologias de escrita proporcionam letramentos diferentes (SOARES, 2002).

A metodologia proposta para a Modalidade EJA preocupa-se não somente com a qualidade metodológica e técnica para a aprendizagem efetiva, mas também com a formação e ampliação das potencialidades dos educandos e a reestruturação de valores, visando garantir o desenvolvimento e formação de cidadãos críticos e autônomos capazes de interagir em sociedade. Os conteúdos devem ser significativos, construídos e trabalhados, considerando a capacidade do educando, suas possibilidades cognitivas e afetivas, respeitando os conhecimentos adquiridos pelos jovens e adultos na sua vida cotidiana. Na avaliação da produção do conhecimento, os aspectos qualitativos preponderam sobre os aspectos quantitativos, em relação a todas as áreas do conhecimento escolar. O processo de avaliação é diário e o estudante tente a ser comparado com suas próprias produções de início de semestre. Assim, comparando o desempenho do discente com ele mesmo é possível observar sua evolução, avanço ou se está em processo. Tais aspectos fazem parte do cotidiano da escola pesquisada, como proposto pela equipe diretiva e corpo docente.

A EJA, principalmente, nas suas práticas pedagógicas deve poder considerar o alunado nas suas demandas específicas; e os conteúdos curriculares a serem utilizados para essa clientela devem acolher os anseios e desejos desses jovens e adultos em vivenciar no ambiente educacional experiências que enriquecem suas vidas. Portanto, utilizar-se de ferramentas e dispositivos tecnológicos implica na promoção de práticas sociais de leitura e escrita em contextos que irão além dos conteúdos de alfabetização regular, ou os esperados pelos educandos da modalidade EJA.

Como maneiras de minimizar os desafios da modalidade EJA se pode sugerir algumas questões. Uma das questões pode ser definida sobre as políticas públicas para a Educação de Jovens e Adultos e sua abrangência. Outra questão é que as equipes de profissionais que atuam na modalidade devem buscar capacitação para 
uso das tecnologias da informação e comunicação para sua prática docente e com o objetivo de inserir seus estudantes no mundo digital (SILVA \& SILVA, 2017).

As diferentes tecnologias de escrita irão proporcionar diferentes alfabetizações (DA SILVA, AZEVEDO, DE ANDRADE,2012; LOPES \& BURGARDT, 2013). uso das TICs transpõe barreiras relacionadas a idade, defasagem escolar e questões econômicas. Os estudantes, com o uso das tecnologias, podem trabalhar suas habilidades, melhorar seu conhecimento e até melhorar sua vida profissional (BARROS, SILVA \& CISESKI, 2018). Com o intuito de verificar como isso acontece na modalidade, elencando as possíveis formas de alfabetização e letramento digital esse trabalho se tornou apropriado.

Como um fator de limitação, cumpre destacar o reduzido número de estudantes que participaram do presente estudo. Como sugestão para estudos futuros, além de aumentar o número de estudantes participantes, se faz necessário avaliar o letramento dos educadores da modalidade EJA sobre as tecnologias da informação e seu uso em sala de aula. Assim, permanece válido seguir em estudos pesquisando sobre essa temática.

\section{REFERÊNCIAS}

BARDIN. L. Análise de conteúdo. Lisboa: Editora Edições 70, 1977.

BARROS, R. M.R.; SILVA, L. S. M.; CISESKI, C. S. B.. Inclusão digital e educação: emergências do mundo globalizado. Colóquio Luso-Brasileiro de Educação-COLBEDUCA, v. 3, 2018.

BINS, Katiuscha Lara Genro. Aspectos psicosócioculturais envolvidos na alfabetização de jovens e adultos deficientes mentais. Porto Alegre, RS, $2007 . \quad$ f.105. Dissertação (Mestrado em Educação) - Faculdade de Educação da PUCRS, Porto Alegre, 2007.

BRASIL. Ministério da Educação. Lei no 9394/96, Lei de Diretrizes e Bases da Educação Nacional. Diário oficial da República Federativa do Brasil. Brasília, DF, 1996.

COSCARELLI, C. V. Letramento digital no INAF. Linguagem e Ensino, v. 20, n. 1, 2017.

DA SILVA, N.; AZEVEDO, C.; DE ANDRADE, M. S. A relação entre escolaridade e uso do computador: aspectos quantitativos de um estudo de caso junto a adultos pouco escolarizados na cidade de São Paulo. Acolhendo a Alfabetização nos Países de Língua Portuguesa, v. 6, n. 12, p. 7-24, 2012. Disponível em: <www.revistas.usp.br/reaa/article/view/ 45583>. Acesso em 07 de janeiro de 2017. 
DE SOUZA SILVA, J.; SILVA, E.; DE ALBUQUERQUE, C. H. Alfabetização Digital para Professores da Educação Básica: Um Relato de Experiência. In: Anais do Workshop de Informática na Escola. 2016. p. 855. Disponível em: www.br-ie.org/pub/index.php/wie/article/ download/6629/4540. Acesso em 07 de janeiro de 2017.

JOAQUIM, B.S.; PESCE, L. As Tecnologias Digitais da Informação e da Comunicação nos Contextos da Educação de Jovens e Adultos: Uma Revisão de Literatura (2007-2014). Olh@res, v. 4, n. 1, p. 86-106, 2016.

INEP. Instituto Nacional de Estudos e Pesquisas Educacionais Anísio Teixeira. Censo da educação básica: 2011 - resumo técnico. - Brasília: Instituto Nacional de Estudos e Pesquisas Educacionais Anísio Teixeira, 2012.

LIMA, S. C.; ALMEIDA, L. V. O. S. Letramento digital de idoso no contexto da EJA em Mossoró-RN. \#Tear: Revista de Educação, Ciência e Tecnologia, v. 4, n. 1, 2015.

LOPES, A.P. N.; BURGARDT, V. M. Idoso: um perfil de alunos na EJA e no mercado de trabalho. Estudos Interdisciplinares sobre o Envelhecimento, v. 18, n.2, 2013.

MATIAS, A. F.; DE FIGUEIREDO, R. V.. Letramento Digital e Interação de Jovens com Deficiência Intelectual a partir do Blog Pessoal. Revista e-Curriculum, v. 16, n. 1, p. 213240, 2018.

MINAYO, M. C. S. O desafio do conhecimento. Pesquisa qualitativa em saúde. São Paulo: HUCITEC, 2007.

MORAES, S.C. Alunos "diferentes" e saberes docentes. In: LOCH, J. M. P. et al. EJA planejamento, metodologias e avaliações. Porto Alegre: Editora Mediação, p. 91-98, 2009.

MORAES, S.C. Socializando as reflexões sobre a criação do SEJA. In: Nogueira, Sandra Vidal et al. Saberes e práticas de ensino e pesquisa. Canoas: Unilasalle, p. 87-96, 2006.

NUNCIATO, R.C. Inclusão Digital: Uma Experiência com Alunos da EJA. Campinas. Universidade Estadual de Campinas. 2009.

RIBEIRO, Gabriela et al. Software livre como ferramenta no processo do ensino aprendizado: uma experiência com turmas do eja. In: Anais do Workshop de Informática na Escola. 2017. p. 974.

SILVA, A.; SILVA, E. M. Práticas de letramento digital de nativos e imigrantes digitais na organização do trabalho pedagógico de sala de aula na EJA. In: Anais do Congresso de Ensino, Pesquisa e Extensão da UEG (CEPE)(ISSN 2447-8687). 2017.

SILVA, W. B.; CASTRO, P. A. Perseu e Medusa: Os Enfrentamentos das Práticas Escolares de Letramento Digital do Professor. e-Mosaicos, v. 6, n. 11, p. 64-72, 2017.

SOARES, M. Novas práticas de leitura e escrita: letramento na cibercultura. Educação \& Sociedade, v. 23, n. 81, 2002.

STOBÄUS, C. D.; BINS, K. G.; MOSQUERA, J. J. M. Adultez e deficiência mental na educação inclusiva. Revista Educação Especial, v. 25, n. 43, 2012. 
VASCONCELOS, A. P. S.; DA SILVA, S. G. P.; DA SILVA, C. A. V.. Perspectivas e desafios no uso das tecnologias digitais no ensino da EJA. Encontro Internacional de Formação de Professores e Fórum Permanente de Inovação Educacional, v. 11, n. 1, 2018.

YIN, R. K. Estudo de Caso: Planejamento e Métodos. 3. Ed. Porto Alegre: Bookman, 2005.

Recebido em: 01-07-2018

Aprovado em: 18-03-2019 